\title{
O ENSINO DE FILOSOFIA DA EDUCAÇÃO EM QUESTÃO
}

Maria Betânia B. Albuquerque

\section{Universidade do Estado do Pará mbbxavier@ig.com.br}

Uma etapa significativa na vida de uma disciplina é o seu envolvimento com os estudos pós-graduados, seja com as pesquisas ou com os eventos. Na década de 70 a Filosofia da Educação vivenciou a inserção nesse âmbito, através da criação do primeiro curso de pósgraduação, no Brasil, em Filosofia da Educação, cujos frutos foram significativos na direção da profissionalização e expansão das pesquisas na área. Trata-se do programa de estudos pós-graduados em Filosofia da Educação da PUC-SP.1 [1]

\footnotetext{
Atuando como centro irradiador, esse programa contribuiu para a criação de outros cursos de pós-graduação no país, com espaço para a investigação em Filosofia da Educação. Entretanto, embora seja inegável a contribuição desses programas para o desenvolvimento de uma cultura investigativa na área da Filosofia da Educação, ainda têm sido limitadas as pesquisas relacionadas à situação da Filosofia da Educação como disciplina acadêmica, sobretudo as que se referem ao seu ensino, as quais tem sido uma raridade.
}

Vasculhando o banco de dissertações e teses da CAPES foi possível, entretanto, localizar alguns exemplos2 [2] . São eles: A Filosofia da Educação na sala de aula da universidade: um estudo de caso (VALENTIM, 2001); O ensino de Filosofia da Educação no Brasil: Uma análise dos programas de ensino de Filosofia da Educação dos cursos de Pedagogia do Estado de São Paulo (1988-1998) (QUILLICI NETO, 2001) e ainda O ensino de filosofia da educação no ensino médio de Campinas-SP: da crise de identidade a desestruturação institucional pós- LDBEN (SILVA, 2003). Na década de 90 duas pesquisas se destacam: Filosofia da Educação: uma disciplina entre a dispersão de conteúdos e a busca de uma identidade (ALBUQUERQUE, 1996) e Concepções teóricas e práticas pedagógicas no ensino da Filosofia da Educação: elementos para discussão de sua identidade (GUARDE, 1998).

A partir de uma perspectiva histórica, três trabalhos também merecem ser destacados. São eles: Filosofia da Educação: uma contribuição à compreensão do seu percurso no campo educacional (TOMAZETTI, 2000); A cadeira de História e Filosofia da Educação da USP

1 [1] A partir de 1998, esse programa deixou de ter a Filosofia da Educação como foco de análise. Chama-se desde então: Estudos pós-graduados em Educação: história, política, sociedade.

2 [2] Breve levantamento via internet das dissertações e teses acerca da temática em questão entre os anos de 1990, 2000, 2001, 2002 e 2003. 
entre os anos 40 e 60: Um estudo das relações entre a vida acadêmica e a grande imprensa (BONTEMPI JR, 2001) e Trilhas e temas da disciplina Filosofia da Educação a partir da PUC-SP (ALBUQUERQUE, 2002).

\section{A investigação sobre o ensino de Filosofia da Educação no âmbito do GT da ANPED.}

No ano de 1994 organizou-se, no contexto da $17^{\text {a }}$ Reunião a ANPED, o primeiro encontro de pesquisadores da área de Filosofia da Educação. Nessa reunião, Antônio J. Severino (1993) apresentou um texto explicitando o universo temático para a investigação em Filosofia da Educação e suas perspectivas de abordagem, iniciando, assim, uma seqüência de discussões em torno do tema. Entendendo a Filosofia da Educação como "esforço para o desvendamento do sentido da educação no contexto do sentido da existência humana" (Ibid., p. 16), o autor propõe três campos temáticos de investigação: o epistemológico, o axiológico e o ontológico.

No âmbito epistemológico destaca como temáticas centrais: a questão do estatuto da Filosofia da Educação; a educação e a construção do conhecimento - os paradigmas epistemológicos em educação, as situações de transmissão e apropriação do conhecimento, a questão do estatuto epistemológico da própria educação, a problemática da linguagem e da clareza conceitual do conhecimento educacional, a significação ideológica do discurso pedagógico.

No âmbito axiológico destacam-se as temáticas: o sentido da educação como prática social; relações entre educação e trabalho; as implicações políticas da prática educacional; relações entre educação e prática cultural; a significação ética da educação; e a dimensão estética da pedagogia. No âmbito ontológico as temáticas: a educação enquanto processo de humanização; a existência humana nas suas múltiplas relações; os processos de individuação; de personalização e de construção de identidade; a educação e a liberdade da pessoa humana, sua dignidade e transcendência.

Ao término da Reunião de 1994, o grupo propôs "a realização de uma sessão especial sobre a identidade do GT- Filosofia da Educação..." elegendo como critério de seleção dos futuros trabalhos maior pertinência à abordagem filosófico-educacional. (ANPED, 1994, Boletim, $n^{\circ} 2$, p. 194). Essa proposição foi considerada necessária à medida que a maioria dos trabalhos e comunicações apresentados no GT não se situava no universo propriamente da Filosofia da Educação, voltando-se ora para o campo exclusivo da Filosofia ora para outros campos do conhecimento educacional configurando, com isso, uma certa dispersividade temática.

Na Reunião de 1995, entretanto, nada ocorreu quanto a discutir a questão da identidade da Filosofia da Educação. O relatório final, novamente, reafirma a necessidade de configuração da identidade do GT não só no sentido de "caracterizar bem o seu perfil, mas também delinear um campo específico de investigação em sua área." (ANPED, 1995b, Relatório final, p. 2 ). 
Em 1997, o debate sobre a temática da identidade da Filosofia da Educação ganhou contorno mais nítido, quer no sentido de reafirmar a necessidade de se enfrentar mais profundamente a questão, quer no sentido de demonstrar a impossibilidade de uma tal proposição. Nesse segundo sentido, destacou-se o trabalho apresentado por Hans-Georg Flickinger sob o título : Para que Filosofia da Educação: 11 teses.

Nesse texto, o autor entende por Filosofia da Educação "a preocupação intelectual capaz de levar os integrantes do processo educativo a um comportamento refletido que os obrigue a dar-se conta dos pressupostos e das implicações, determinantes do perfil profissional do educador" (FLICKINGER, 1998, p. 16). Na ausência desse comportamento refletido, os profissionais da educação teriam um agir norteado por uma racionalidade oculta. Todavia exatamente por ser um comportamento reflexivo ou uma postura, esta deveria perpassar todo o procedimento educativo o que, por sua vez, contradiz a idéia de necessidade da Filosofia da Educação enquanto disciplina diferenciada no campo educacional.

Na sua visão, "a Filosofia da Educação não pode assumir o lugar de uma meta-teoria ou de uma fundamentação teórica do agir" do educador, como é freqüentemente interpretada. Para ele, se os profissionais da educação aceitassem a postura refletida como um "pressuposto incontestável", esta "passaria a integrar o processo educativo, a ponto de tornar supérflua a necessidade da experiência filosófica, injetada enquanto disciplina ao educador"(FLICKINGER, 1998, p. 22, grifo meu).

O outro trabalho destacado no ano de 1997 intitulou-se: Filosofia da Educação: Para quê? de autoria de Bruno Pucci, o qual se propôs a recuperar algumas características históricas da Filosofia. Apoiando-se no pensamento de Adorno, disserta sobre tais características, entre elas: o pensar autônomo como instrumento primeiro da formação do espírito; a necessidade da razão voltar a ser negativa; a crença na potencialidade do conceito como instrumento de intervenção; e o potencial estético da Filosofia.

Entretanto, não se encontra no texto de Pucci algo próximo da resposta à pergunta por ele enunciada - Filosofia da Educação: para quê? Apesar de afirmar que "entender a fundo a força que constitui historicamente a filosofia é pressuposto indispensável para refletir sobre os problemas da educação nos dias de hoje" (PUCCI, 1998, p. 23), não entra nessa problemática, limitando seu texto à descrição daquilo que, segundo Adorno, caracteriza a Filosofia. Deste modo, confirma a tendência existente na literatura filosófico-educacional que é a de enfatizar somente a Filosofia, tratando as implicações educacionais como mera conclusão do texto, sem espaço para a explicitação da possível correlação entre Filosofia $e$ Educação.

Destacou-se, também, no ano de 1997, o trabalho intitulado Filosofia da Educação: uma disciplina entre a dispersão de conteúdos e a ausência de uma identidade. O texto apresentou as principais conclusões da dissertação de mestrado de Albuquerque, anteriormente mencionada, resultante de uma pesquisa realizada em dez universidades públicas situadas em diferentes estados brasileiros. Nesse estudo, a autora fez uma análise dos programas de ensino da disciplina Filosofia da Educação e da concepção teórica de 
alguns dos principais intelectuais da área, utilizando seus textos e depoimentos concedidos em entrevista; investigou a formação acadêmica e os principais investimentos intelectuais feitos nessa área pelos profissionais das dez universidades selecionadas.

Com conclusões pouco otimistas, os resultados da pesquisa revelaram, entre outras coisas: a postura preconceituosa com que a disciplina Filosofia da Educação é vista nos meios filosóficos, isto é, como coisa de pedagogos, a tendência dos próprios intelectuais da Filosofia da Educação de dissertar muito mais sobre os aspectos puramente filosóficos, deixando a educação como mera conclusão dos seus textos; a dispersividade temática constitutiva dos programas de Filosofia da Educação; a carência de investimentos intelectuais na área, em termos de artigos, livros, dissertações e teses, além da precariedade de instâncias de consagração e legitimação das suas produções. Com base nesses resultados, a pesquisa ressaltou, diferentemente da perspectiva da superfluidade da Filosofia da Educação, a necessidade de um redimensionamento da disciplina, com vista à construção de novos projetos filosóficos para a educação.

Embora o texto não tenha entrado no âmbito da questão específica da relação entre filosofia e educação, ele quis provocar o debate sobre um ângulo da Filosofia da Educação que tem tido pouco investimento intelectual entre os filósofos da educação: o do seu ensino. Além disso, o texto de Albuquerque (1998), por entrar no cerne da situação da disciplina Filosofia da Educação na universidade brasileira, induziu a uma ampliação do debate sobre a questão complexa da identidade da Filosofia da Educação.

Ao final da reunião de 1997, ficou decidido que o trabalho encomendado para o ano de 1998 deveria versar sobre a questão da identidade da Filosofia da Educação e que, em 1999, a temática a nortear $50 \%$ dos trabalhos deveria se centrar na questão do ensino de Filosofia da Educação. Entretanto, como todo campo é espaço de lutas e de conflitos a definição dessa temática gerou certa polêmica entre os participantes do GT. Maria Célia Moraes (1998), afirmou, por exemplo:3 [3]

Caros colegas do GT, concordo com os colegas que se posicionam contrários à escolha da temática do ensino de Filosofia da Educação para o próximo encontro. As discussões sobre os 'ensinos de' acabam se revelando sempre muito restritas. E seria uma pena desperdiçar a riqueza temática oferecida pela filosofia. Concordo com os que propõem 'ética e educação' que possibilita amplas e atualíssimas reflexões (grifo meu).

Numa direção semelhante, caminha o depoimento do professor Silvio Gallo (1998a), para quem a discussão sobre ensino de Filosofia da Educação é alguma coisa "preocupante" e "incômoda":

Penso que a estratégia (definição de tema geral com 2 anos de antecedência) está ok, mas volto a dizer que me incomoda o tema acima, por compreendê-lo como muito redutor. $\mathrm{O}$

3 [3] A lista de discussão na internet: filosed@ufpel.tche.br, constituiu-se num espaço privilegiado de lutas pela imposição dos pontos de vistas diferenciados engendrados pela discussão sobre ensino de Filosofia da Educação. 
Renato indica 2 temas amplos e muito mais interessantes, que não deixam de fazer interfaces com a questão do ensino. Repito que para uma associação voltada para a discussão de pesquisa em educação, gastar o espaço de 7 trabalhos em 12 que temos para discutir o ensino é preocupante, pois resta muito pouco espaço para o debate das pesquisas desenvolvidas na área (grifo meu).

Num depoimento posterior, Silvio Gallo (1998b) refez, em parte, o posicionamento acima: "Reitero que penso que o fórum para discutir ensino é outro. Por outro lado, debater o ensino que fazemos da Filosofia da Educação para assim clarearmos sua identidade e seu sentido, é outra coisa, e estou plenamente de acordo".

Do lado dos que se manifestaram de modo favorável a um maior delineamento da disciplina, para que filosofia e educação possam, de fato, interligar-se, há o depoimento de Lílian do Valle (1998):

Caro Severino, gostei muito das questões que você comunicou ao GT. Pessoalmente, considero bastante equivocadas as posições que insistem em valorizar a 'discussão filosófica' livre, sem muito compromisso com a área da educação. Não consigo entender muito bem o sentido de se manter um grupo assim na Anped. Tanto quanto não consigo entender, por exemplo, que os colegas consagrem seus trabalhos ao pensamento de um autor, sem interrogar este que é o nosso ponto de interesse comum, nem sequer de passagem. A discussão sobre o ensino da filosofia, ainda que seja apenas um aspecto da questão maior (que é a da própria elucidação filosófica da educação) parece corresponder muito mais ao que deve ser um GT de Filosofia DA EDUCAÇÃO na Anped.

Apesar do confronto virtual entre posições intelectuais distintas, os debates em torno do tema da identidade da Filosofia da Educação tiveram continuidade no ano $1998 \mathrm{com}$ a apresentação do trabalho de Newton Aquiles Von Zuben (1998), cujo próprio título, Identidade da Filosofia da Educação, parecia bastante instigador. Neste texto, o autor não se preocupa com "estabelecer critérios sobre os quais poderia apoiar-se a justificativa de uma 'demarche' de reflexão filosófica da educação", porque no seu entender, "a Filosofia da Educação não tem que justificar sua existência e seu projeto" posto que "sua maioridade no âmbito da Filosofia já está assegurada” (VON ZUBEN, 1998, p. 2).

Não necessitando a Filosofia da Educação de qualquer justificativa quanto ao seu projeto, o autor, então, disserta sobre o pensamento de Edgar Morin e sua possível aplicação ao campo filosófico-educacional, não adentrando na discussão suscitada pelo próprio título do seu texto, isto é, a identidade da Filosofia da Educação.

Outro trabalho que despertou atenção na reunião de 1998, intitulou-se Filosofia da Educação: uma outra Filosofia? de Tarso Bonilha Mazzotti (UFRJ). O texto parte da idéia de que a tarefa central da Filosofia da Educação é a de elucidar o conhecimento educacional, particularmente, as teorias pedagógicas, por meio das análises lógicas, dialéticas e retóricas, carecendo examiná-las com cuidado para verificar sua pertinência e adequação. E por serem constituídas a partir das ciências que examinam o humano em suas múltiplas dimensões, necessitam de validação de alguma maneira. Neste sentido, o autor considera a Filosofia da Educação como uma filosofia das ciências da educação que se faz enquanto "coordenação interdisciplinar da Pedagogia" (MAZZOTTI, 1999, p. 201). 
A crítica às teorias pedagógicas exige a análise de seus enunciados a fim de se "aferir suas qualidades lógicas e de adequação ao contexto, de modo a favorecer ações mais eficazes" (Ibid., p. 201), visto que estas teorias procuram expor os processos educativos tendo por horizonte o desejável ou os valores que, em dado momento, são considerados socialmente relevantes. Conquanto se considere que as práticas educativas se manifestam quase sempre de modo ineficaz em relação ao que se considera valioso, torna-se necessário a explicitação das determinações que as envolvem. A apreensão dessas práticas é feita pelas diversas ciências, entretanto, estas precisam ser coordenadas através do estabelecimento de um percurso, de um método que é dado pela Filosofia da Educação. Nas palavras do autor:

Por essas considerações quero salientar que o ensino da filosofia da educação requer o reexame do estatuto dessa disciplina. Parece-me que nessa revisão é necessário estabelecer o instrumental adequado ao exame das teorias pedagógicas que seria constituído, no mínimo, pelas diversas lógicas, entre elas, a lógica erotética, ou do questionamento, pela 'nova retórica'. Isto significa que o ensino da filosofia da educação deve ser um exercício de aquisição do instrumental crítico constituído pelas lógicas, pela dialética e pela retórica, tal como se tem desenvolvido em nossos dias (MAZZOTTI, 1999, p. 204, grifo meu).

Finalmente, depois de tantas polêmicas em torno da questão de se discutir, ou não, o ensino de Filosofia da Educação no ano de 1999, optou-se por uma posição conciliatória conforme expressa o depoimento de Avelino Oliveira (1998):

Tomei conhecimento da polêmica desencadeada por comunicações do professor Silvio Gallo e do Professor Severino, em torno do tema adotado pelo GT-Filosofia da Educação, a saber a questão do ensino da Filosofia da Educação. Pois bem, gostaria de dar minhas cartas, também, nesse jogo que me é bastante interessante, pois pode levar-nos a idéias mais claras sobre o que queremos em nosso GT. Concordo com o Silvio Gallo, quando ele defende o espaço do GT como espaço privilegiado para a comunicação de pesquisas. Mas concordo também com o Severino quando ele reitera a importância de que o GT, pelo menos por um momento, volte seus olhos para o ensino. Concordo com ambos porque não vejo o ensino da filosofia da educação como apartado da pesquisa em filosofia da educação e vice-versa...

Em 1999, o GT- Filosofia da Educação reuniu-se em torno de doze trabalhos.4 [4] Contudo, eles não abordam, diretamente, a temática do ensino de Filosofia da Educação. Dois trabalhos, no entanto, se aproximaram do tema. No primeiro O que é filosofia da educação: Anotações a partir de Deleuze e Guatarri - o autor, Silvio Gallo (1999, p. 12), indaga sobre "o que é possível de ser dito sobre Educação, a partir de Deleuze?". Para ele, na tradição da Filosofia da Educação, no Brasil, tem sido comum entendê-la como uma "reflexão sobre os problemas educacionais" (Ibid., p. 12). Concordando com Deleuze, o autor considera que não existe "nada mais pobre e reducionista para a filosofia da educação do que tomá-la como reflexão sobre a educação" (Ibid., p. 12), posto que,

[4] Os trabalhos apresentados na reunião do GT de 1999, foram publicados na revista Perspectiva, $\mathrm{n}^{\mathbf{o}} 34$, jul/dez 2000. No entanto, as citações dos textos selecionados foram extraídas no momento em que eles ainda não haviam sido publicados. 
Sempre que se está numa época pobre, a filosofia se refugia na reflexão 'sobre'(...) Se ela mesma nada cria, o que poderia fazer, senão refletir sobre? Então reflete sobre o eterno, ou sobre o histórico, mas já não consegue ela própria fazer o movimento. De fato, o que importa é retirar do filósofo o direito à reflexão 'sobre'. O filósofo é criador, ele não é reflexivo (Deleuze, Apud GALLO, 1999, p. 12).

Considerando este ponto de vista de Deleuze, "facilmente extensível à filosofia da educação" (GALLO, 1999, p. 13), o autor afirma que "em épocas de penúria para a filosofia, ela refugia-se na reflexão sobre a educação..." e não sendo essa reflexão específica da filosofia, é necessário que "combatamos a noção de filosofia da educação como reflexão sobre a educação" posto que "ela deve ser muito mais do que isso" (Ibid., p. 13).

Para Silvio Gallo, outra perspectiva da Filosofia da Educação a ser combatida é a de fundamentos da educação, segundo a qual ela deve fornecer as bases de sustentação do processo educativo. Em geral, diz o autor, para cumprir essa tarefa, a Filosofia da Educação "parte em busca dos conceitos produzidos por filósofos, ao longo da história, para sobre eles erigir um saber educacional" (GALLO, 1999, p. 14). Ao indagar sobre a utilidade desse procedimento, Gallo recorre, tal como está criticando, ao pensamento de Deleuze.

Silvio Gallo entende que "a inspiração deleuziana é bastante interessante" (Ibid., p. 14) para quem "o filósofo da educação deve ser um criador de conceitos" além de que "deve ter intimidade com os problemas educacionais" (Ibid., p. 15). De posse desse conhecimento, "trata-se, então, de aplicar a eles, [aos] problemas educacionais, o instrumental filosófico" (Ibid., p. 15). Segundo o autor:

A tarefa do filósofo da educação é a de pensar filosoficamente questões colocadas pelo plano de imanência que atravessa transversalmente o campo de saberes em que se constitui a educação. Mas que entendamos bem: os problemas colocados por tal plano de imanência tendem ao infinito; eles não estão circunscritos apenas à Educação. Isto é, os problemas de que trata a filosofia, suscitados pela educação, não são exclusivamente educacionais, mas muito mais abrangentes; se não fosse assim, teríamos novamente a filosofia da educação como uma "reflexão sobre a educação". Desta maneira, o filósofo da educação é, antes de qualquer coisa, filósofo (GALLO, 1999, p. 15).

No segundo texto - A educação como enigma e como atividade prático-poiética: implicaçôes para o ensino da Filosofia da Educação - Lílian do Valle (1999), considerando o desprestígio da teoria e da filosofia no meio pedagógico, afirma que a reflexão sobre o ensino da Filosofia da Educação torna-se especialmente necessária e urgente. No entanto, esta reflexão pressupõe indagar tanto sobre o que é a filosofia da educação quanto sobre o que é a filosofia.

Para a autora, a formulação das duas questões "provoca um certo embaraço" (VALLE, 1999, p. 1) em função da desconfiança para com as "definições acabadas e dogmáticas" (Ibid., p. 1). Este embaraço se explica pela concepção de Filosofia como saber capaz de "estipular o lugar das demais disciplinas" (Ibid., p. 2) e de "guiá-las em seu caminho, fixando princípios e procedimentos para sua atuação" (Ibid., p. 2). Além disto, há o 
problema do "pedantismo" e da "arrogância" (Ibid., p. 2), conseqüência dessa concepção que imprimiu à filosofia uma "imagem de hermetismo e de inacessibilidade" (Ibid., p. 2). Neste sentido, pergunta a autora: "deveríamos renunciar, também, à exigência de pensar o que a prática do ensino da filosofia da educação tem de próprio?” (VALLE, 1999, p. 2). "Do que, afinal, tratamos, ao falar em filosofia da educação?" (Ibid., p. 2).

Lílian do Valle (1999, p. 3) reforça que o ensino de Filosofia da Educação se traduz como uma "exigência de interrogação dos sentidos que são próprios à educação", destacando "o caráter marcadamente expositivo com que toda uma procissão de autores era convocada a apresentar suas contribuições" (Ibid., p. 3) acerca da educação, sob a forma supostamente crítica de correntes de pensamento. Uma alternativa apresentada a esse estado de coisas baseia-se em Cornelius Castoriadis, para quem a filosofia "é compromisso com a totalidade do pensável" (Ibid., p. 4), não como "totalidade daquilo que já foi pensado, mas com a totalidade daquilo que há para pensar" (Ibid., p 3-4). Ou seja, a essencialidade da filosofia para com a educação, está no fato de ela se fazer "compromisso de interrogação permanente" (Ibid., p. 4), pois somente assim ela se torna "prática de emancipação" e "terreno de luta pela autonomia" (VALLE, 1999, p. 4).

Ao definir a Filosofia da Educação "pela exigência de uma interrogação que, antes de ser seu monopólio, é tarefa de autocriação individual e coletiva" (VALLE, 1999, p. 13), cujo ponto de partida e fim é a emancipação humana, a autora conclui pela "importância essencial a ser concedida a seu ensino" (Ibid., p. 13).

Eis, portanto, em que se resumiu o debate sobre o ensino de Filosofia da Educação. Os demais textos apresentados seguiram a clássica tendência de se apropriar do pensamento de um filósofo e extrair dele conseqüências para a educação. Ao ser interrogada sobre o avanço, ou não, desse debate no GT a coordenadora em exercício respondeu:

Para dizê-lo de forma abrupta, primeiramente acho que há a questão da identidade da Filosofia da Educação, ou melhor, de sua ausência. Em outras palavras, penso que nós do GT, tanto quanto os militantes da área, não temos investido muito esforço em prestar contas aos outros do que faz a singularidade de nossa área, e temos debatido muitíssimo pouco acerca de nossas diferenças. Dessa forma, nada se constrói em comum.5 [5]

Diante disso, conclui-se que as discussões acerca da identidade da Filosofia da Educação, iniciadas no GT em 1994, contribuiu para um despertar dos profissionais quanto a essa questão, mas não logrou grande alcance em termos de um repensar mais substancial da área. Essa situação induz a pensar acerca de uma outra possibilidade de produção $e$ atuação no campo da Filosofia da Educação, qual seja: a criação de espaços de discussões sobre sua própria condição, viabilizando uma dimensão tão cara à filosofia - a epistemológica. Permanece, portanto, em aberto, a pergunta sobre quais as questões que estão hoje a demandar uma reflexão filosófico-educacional ou, como pergunta Rios (2001, p. 46): "o que provoca nosso espanto, hoje?" São questões que merecem ser debatidas.

[5] Lílian do Valle, depoimento via e-mail em 09/04/02. 


\section{REFERÊNCIA BIBLIOGRÁFICA}

ALBUQUERQUE, Maria Betânia B. Filosofia da Educação: uma disciplina entre a dispersão de conteúdos e a busca de uma identidade. Belo Horizonte, MG: 1996. Originalmente apresentada como dissertação de mestrado, Faculdade de Educação da UFMG/MG,1996.

. Filosofia da educação: uma disciplina entre a dispersão de conteúdos e a ausência de uma identidade. Perspectiva, Florianópolis, vol 16, n 29, jan/jun, pp. 45-61. 1998.

. Trilhas e temas da Filosofia da Educação a partir da PUC/SP. São Paulo, SP: 2003. Originalmente apresentada como tese de doutorado, Programa de Estudos pósgraduados em educação: história, política, sociedade, PUC/SP, 2003.

BONTEMPI JÚNIOR, B. A cadeira de História e Filosofia da Educação da USP entre os anos 40 e 60: um estudo das relações entre a vida acadêmica e a grande imprensa. São Paulo, SP: 2001. Originalmente apresentada como tese de doutorado, Programa de Estudos pós-graduados em educação: história, política, sociedade, PUC/SP, 2001.

FLICKINGER, Hans-Georg. Para que filosofia da educação: 11 teses. Perspectiva, Florianópolis, v. 16, n²9, pp. 15-22. 1998.

GALLO, Silvio. Temas para 1998. [Filosed] 1998a. Disponível em: < filosed@ufpel.tche.br>. Acesso em: 02 de março de 1998.

. Reunião anped. [Filosed]. 1998b.. Disponível em: < filosed@ufpel.tche.br >. Acesso em: 09 de abril de 1998.

. O que é filosofia da educação: anotações a partir de Deleuze e Guatarri. In: GT-

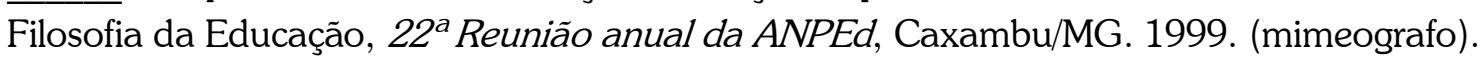

GUARDE, Silvio. Concepções teóricas e práticas pedagógicas no ensino da filosofia da educação: elementos para discussão de sua identidade. São Paulo, SP: 1998.

Originalmente apresentada como dissertação de mestrado, Centro Universitário Salesiano de São Paulo. 1998.

MAZZOTTI, Tarso. Filosofia da educação: uma outra filosofia? In: GHIRALDELLI Jr., Paulo (org.). O que é filosofia da educação? Rio de Janeiro: DP\&A, pp. 187-206. 1999.

MORAES, Maria Célia. Temas para o GT. [Filosed]. 1998. Disponível em: < filosed@ufpel.tche.br>. Acesso em: 01 de março de 1998.

OLIVEIRA, Avelino. Contribuição do Ghiraldelli. [Filosed]. 1998. Disponível em: <年losed@ufpel.tche.br>. Acesso em 10 de abril de 1998. 
PUCCI, Bruno. Filosofia da educação para quê? Perspectiva, Florianópolis, v. 16, n²9, pp. 23-43. 1998.

QUILLICI NETO, Armindo. O ensino de Filosofia da Educação no Brasil: Uma análise dos programas de ensino de Filosofia da Educação dos cursos de Pedagogia do Estado de São Paulo (1988-1998). Campinas, SP: 2001. Originalmente apresentada como tese de doutorado, Faculdade de Educação da Unicamp/SP, 2001.

RIOS, Terezinha A. Compreender e ensinar: por uma docência da melhor qualidade. São Paulo: Cortez, 2001

SEVERINO, Antônio J. Proposta de um universo temático para a investigação em

Filosofia da Educação. Perspectiva, Florianópolis nº 19, jan./jun., pp. 11-27, 1993.

SILVA, Marcelo D. O ensino de filosofia da educação no ensino médio de Campinas-SP: da crise de identidade a desestruturação institucional pós- LDBEN. Campinas, SP: 2003. Originalmente apresentada como dissertação de mestrado, Faculdade de Educação da Unicamp/SP, 2003.

TOMAZETTI, Elisete. Filosofia da educação: uma contribuição à compreensão do seu percurso no campo educacional.São Paulo, SP: 2000. Originalmente apresentada como tese de doutorado, Faculdade de Educação da USP/SP, 2000.

VALENTIM, Lucy M. S. A Filosofia da Educação na sala de aula da universidade: um estudo de caso. São Carlos, SP: 2001. Originalmente apresentada como dissertação de Mestrado, Faculdade de Educação da UFSCAR/SP, 2001.

VALLE, Lílian do. Interrogar-se sobre o sentido do ensino da filosofia da educação. [filosed]. 1998. Disponível em: < filosed@ufpel.tche.br>. Acesso em 05 de abril de 1998.

. A educação como enígma e como atividade prático-poética: implicações para o ensino da filosofia da educação. In: GT-filosofia da educação, $22^{a}$ Reunião anual da ANPEd, Caxambu/MG. 2000. (Mimeografado).

VON ZUBEN, Newton Aquiles. Identidade da filosofia da educação. $21^{a}$ Reunião Anual da ANPEd, Caxambu/MG.1998. (mimeografado).

[1] A partir de 1998, esse programa deixou de ter a Filosofia da Educação como foco de análise. Chama-se desde então: Estudos pós-graduados em Educação: história, política, sociedade.

[2] Breve levantamento via internet das dissertações e teses acerca da temática em questão entre os anos de 1990, 2000, 2001, 2002 e 2003. 
[3] A lista de discussão na internet: filosed@ufpel.tche.br, constituiu-se num espaço privilegiado de lutas pela imposição dos pontos de vistas diferenciados engendrados pela discussão sobre ensino de Filosofia da Educação.

[4] Os trabalhos apresentados na reunião do GT de 1999, foram publicados na revista Perspectiva, $\mathrm{n}^{\circ} 34$, jul/dez 2000. No entanto, as citações dos textos selecionados foram extraídas no momento em que eles ainda não haviam sido publicados.

[5] Lílian do Valle, depoimento via e-mail em 09/04/02. 